\title{
First report on aberrant Ascaris suum infection in a dog, China
}

\author{
Yue Xie ${ }^{1 *+} \mathbb{D}$, Yunjian Liu ${ }^{1 \dagger}$, Xiaobin $\mathrm{Gu}^{1 \dagger}$, Xuan Zhou ${ }^{2}$, Xuerong Peng ${ }^{3}$, Ran He ${ }^{1}$, Hongrui Guo ${ }^{4}$, Zhicai Zuo ${ }^{5}$ \\ and Guangyou Yang ${ }^{1 *}$
}

\begin{abstract}
An aberrant Ascaris suum infection in a domestic dog in China in 2019 is described for the first time. This pathogen is a common roundworm of pigs with few reported cases in domestic animals. Our findings suggest a wider infection range with a possible transmission of $A$. suum to domestic animals that interact with humans.
\end{abstract}

Keywords: Ascariasis, Ascaris suum, Helminthic zoonosis, Host range, Dogs

\section{Letter to the Editor}

Roundworms, belonging to the family Ascarididae, are among the most common zooparasitic nematodes and cause ascariasis in all major lineages of vertebrates including domestic animals, wildlife and humans. Ascaris suum is a common roundworm of pigs. Although pig husbandry has become more modernized and industrialized, A. suum is still prevalent on a large number of pig farms across the world and the situation has not changed significantly over the last few decades [1]. It is evident that A. suum is zoonotic and its cross-infection and hybridization with the human roundworm Ascaris lumbricoides has been recently confirmed in areas of humanpig sympatry [2]. Importantly, cases of A. suum-related human infections have been reported [3-5], including an outbreak in Maine, USA, in 2010-2013 [6]. In addition, aberrant $A$. suum infections were also reported in domestic animals, such as cattle [7]. Here we expand the currently recognized infection spectrum by firstly describing A. suum infection in domestic dogs in China.

In April 2019, a two-month-old female German shepherd dog puppy from a pig farm was brought to

\footnotetext{
*Correspondence: xyue1985@gmail.com; guangyou1963@aliyun.com

${ }^{\dagger}$ Yue Xie, Yunjian Liu and Xiaobin Gu contributed equally to this work

1 Department of Parasitology, College of Veterinary Medicine, Sichuan Agricultural University, Chengdu 611130, China

Full list of author information is available at the end of the article
}

Veterinary Medical Teaching Hospital (VMTH), Sichuan Agricultural University (Sichuan, China), for post-mortem examination. The puppy died with clinical manifestations of dyspnea, coughing, wheezing and general weakness. This farm kept five German shepherd dogs (a bitch and her four puppies), and all the puppies had shown similar clinical signs for about two weeks. Routine vaccinations were administrated to all of the dogs.

Necropsy of the puppy revealed bilateral lungs with significant emphysema and diffusely firm red parenchyma, and the trachea and bronchi were filled with massive blood-tinged froth. Interstitial pneumonia was diagnosed according to the gross appearance, and viral or bacterial pneumonia was suspected. However, histopathological examination showed a diffuse, severe, hemorrhagic, fibrinous interstitial pneumonia with multiple nematode larvae present in alveolar sacs and bronchi which were partially surrounded by inflammatory cells (macrophages, lymphocytes and eosinophils) (Fig. 1a, b). The larvae measured $68 \mu \mathrm{m}$ in maximum transverse diameter and had a thin cuticle that formed sharply pointed paired lateral alae. The intestine was centrally located, floated in pseudocoelom and flanked by large paired triangular excretory columns. Four to five muscle cells were observed per quadrant. These morphological characteristics are key for ascaridid nematodes. Examination of gastrointestinal tracts from the puppy recovered three acaridid nematodes. No viral or bacterial etiology was

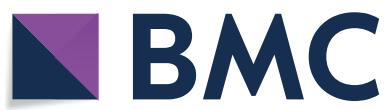

(c) The Author(s) 2020. This article is licensed under a Creative Commons Attribution 4.0 International License, which permits use, sharing, adaptation, distribution and reproduction in any medium or format, as long as you give appropriate credit to the original author(s) and the source, provide a link to the Creative Commons licence, and indicate if changes were made. The images or other third party material in this article are included in the article's Creative Commons licence, unless indicated otherwise in a credit line to the material. If material is not included in the article's Creative Commons licence and your intended use is not permitted by statutory regulation or exceeds the permitted use, you will need to obtain permission directly from the copyright holder. To view a copy of this licence, visit http://creativeco mmons.org/licenses/by/4.0/. The Creative Commons Public Domain Dedication waiver (http://creativecommons.org/publicdomain/ zero/1.0/) applies to the data made available in this article, unless otherwise stated in a credit line to the data. 


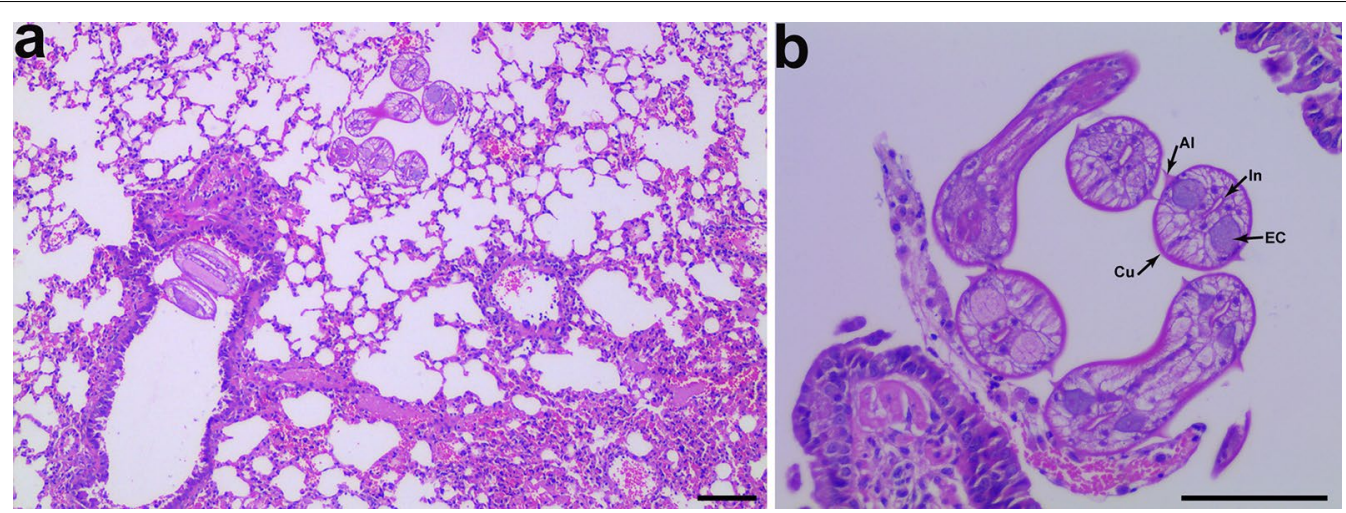

Fig. 1 Morphological characterization of Ascaris suum nematode infection in the lung of a dog in China, 2019. a Multiple transverse sections of A. suum larvae observed in lung tissues with severe, hemorrhagic, fibrinous interstitial pneumonia. b The morphological characteristics of the larvae included maximum diameter of $68 \mu \mathrm{m}$, thin cuticle (Cu), a centrally located intestine (In), paired lateral alae (Al) and excretory columns (EC). Some scattered macrophages, lymphocytes and eosinophils are also indicated. Hematoxylin and eosin stain. Scale-bars: $100 \mu \mathrm{m}$

diagnosed from routine bacteriological and molecular diagnostic tests.

The three acaridid nematodes were provisionally identified as Toxocara canis based on morphology: the presence of a post-oesophageal bulbus, the length and shape of the alae and the length of the spicules. Toxocara canis is a canine roundworm that is highly prevalent in puppies under three months-old and can adopt "hepato-tracheal" migration to develop into adults. Thus, this parasite can also cause histopathological changes of lungs similar to those identified in this study.

To accurately identify the nematodes in the infected lung, genomic DNA was extracted from formalin-fixed, paraffin-embedded (FFPE) tissues and subjected to genetic analysis by sequencing partial fragments of the nuclear $18 S$ ribosomal DNA (18S rDNA) gene [8] and the mitochondrial $12 S$ ribosomal DNA (12S rDNA) gene [9]. The resulting sequences of $18 S$ rDNA (1729 bp; GenBank: MN558962) and $12 S$ rDNA (488 bp; GenBank: MN567666) were found to be $99.9-100 \%$ identical with those of A. suum (GenBank: U94367 and FJ418791, respectively), and both grouped together and were clearly distinct from $T$. canis in phylogenies inferred from either $18 S$ rDNA or $12 S$ rDNA using maximum likelihood and Bayesian inference methods (Fig. 2a, b). Indeed, further investigations supported pigs as the infection source because $c .60 \%$ pigs in this farm were serologically detected as A. suum-positive by AsHb ELISA (Y. Zheng et al., unpublished data) [10], and parasitological examination of soil and water around the pig farm indicated a heavy contamination with $A$. suum eggs. This suggested that the free-range German shepherd dogs were probably exposed to the eggs and became infected.
The pig roundworm $A$. suum has been suggested as causing a widely distributed zoonosis with human cases in North America, Europe and Asia [2, 3, 6]. Some other animals infected with $A$. suum have been also recently reported [7]. Our finding shows that this roundworm can infect dogs. This observation expands the previously acknowledged infection range and raises questions about infection success and host affiliation of A. suum in nature that are difficult to address by traditional biological, epidemiological and clinical approaches. Moreover, in consideration of the cultural and agricultural tradition of using pig feces as fertilizer and the feature that $A$. suum eggs remain viable in farm soil for years as well as the location of pig latrines where dogs easily access, the chance of direct or indirect exposure for dogs is likely. Recommended preventive procedures to reduce transmission of $A$. suum between pigs and dogs, and probably between pigs and humans, include restraining dogs from pig lactrines, periodically examining farm dogs and pigs for infection, prophylactic and therapeutic treatment of pigs to reduce infection, avoiding use of pig manure as fertilizer, and washing hands when there is contact with pigs, pig waste or soil contaminated with pig waste. In addition, the farm owner should have dedicated equipment for handling or depositing animal waste. Because A. suum eggs can persist in the farm surrounding for extended periods, daily foodstuffs, especially produce and vegetables grown using pig manure should be avoided or fed only after thorough cleaning. Overall, an effective prevention of $A$. suum infections requires an integrated "One-Health" approach that encourages 


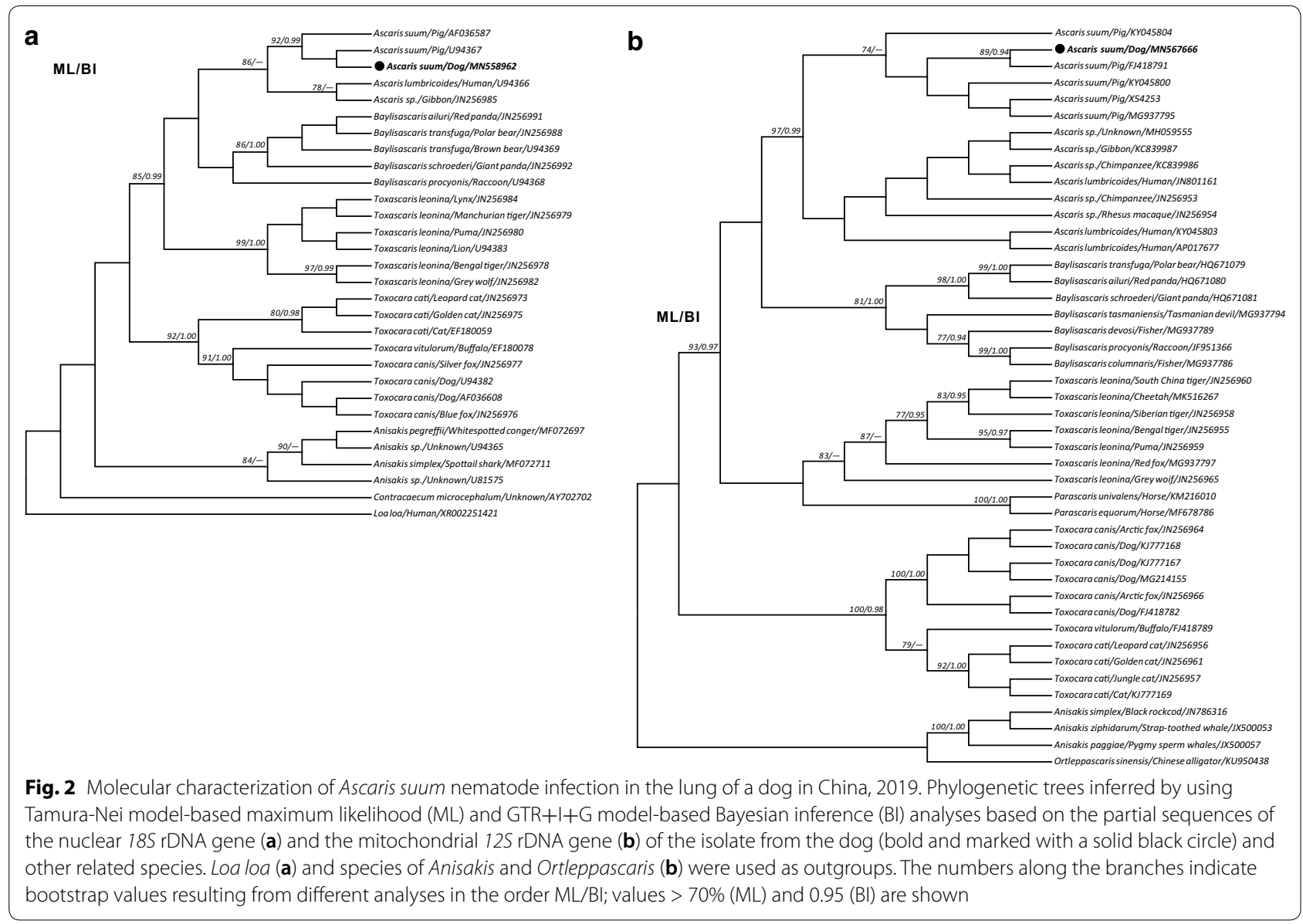

collaboration between farmers, veterinarians and physicians and enhances their awareness to the risk for aberrant infections of $A$. suum and its transmission to humans and other domestic animals.

\section{Acknowledgements}

We thank Dr. Joseph F. Urban, Jr., from USDA-ARS, Beltsville Human Nutrition Research Center, Diet, Genomics and Immunology Laboratory for manuscript review and advice.

\section{Authors' contributions}

YX and GYY conceived and designed the experiments. YJL and XBG performed the experiments, including PCR and sequencing. RH, HRG and ZCZ carried out the histopathologic examination. YX, YJL and XBG achieved the data analysis. $X Z$ and PXR contributed reagents/materials/analysis tools. YX and GYY wrote the initial manuscript. All authors read and approved the final manuscript.

\section{Funding}

This work was supported by the Sichuan International Science and Technology Innovation Cooperation/Hong Kong, Macao and Taiwan Science and Technology Innovation Cooperation Project, Sichuan, China (Grant No. 2019YFH0065) and the High-level Scientific Research Foundation for the Introduction of Talents of Sichuan Agricultural University (No. 03120322). The funders had no role in design, decision to publish, or preparation of the manuscript.

\section{Availability of data and materials}

Nucleotide sequences reported in this article are available in the GenBank database under the accession numbers MN558962 (18S) and MN567666 (12S).

\section{Ethics approval and consent to participate}

This study was approved by the Animal Ethics Committee of Sichuan Agricultural University (China; approval no. SYXK 2014-187), and all procedures including the autopsy were performed in strict accordance with the Guide for the Care and Use of Laboratory Animals (National Research Council, Bethesda, MD, USA) and the recommendations in the ARRIVE guidelines (https://www. nc3rs.org.uk/arrive-guidelines).

\section{Consent for publication}

Not applicable.

\section{Competing interests}

The authors declare that they have no competing interests.

\section{Author details}

${ }^{1}$ Department of Parasitology, College of Veterinary Medicine, Sichuan Agricultural University, Chengdu 611130, China. ${ }^{2}$ Institute of Animal Genetics and Breeding, College of Animal Science and Technology, Sichuan Agricultural University, Chengdu 611130, China. ${ }^{3}$ Department of Chemistry, College of Life and Basic Science, Sichuan Agricultural University, Chengdu 611130, China. ${ }^{4}$ Key Laboratory of Animal Diseases and Environmental Hazards of Sichuan Province, Sichuan Agriculture University, Wenjiang, Chengdu 611130, China. ${ }^{5}$ Key Laboratory of Animal Disease and Human Health of Sichuan 
Province, College of Veterinary Medicine, Sichuan Agricultural University, Chengdu 611130, China.

Received: 1 December 2019 Accepted: 13 February 2020

Published online: 18 February 2020

\section{References}

1. Wang T. Transcriptomic and proteomic analysis of Ascaris suum larvae during their hepato-tracheal migration. Ghent: Ghent University; 2014.

2. Peng W, Criscione CD. Ascariasis in people and pigs: new inferences from DNA analysis of worm populations. Infect Genet Evol. 2012;12:227-35.

3. Bendall RP, Barlow M, Betson M, Stothard JR, Nejsum P. Zoonotic ascariasis, United Kingdom. Emerg Infect Dis. 2011;17:1964-6.

4. Sakakibara A, Baba K, Niwa S, Yagi T, Wakayama H, Yoshida K, et al. Visceral larva migrans due to Ascaris suum which presented with eosinophilic pneumonia and multiple intra-hepatic lesions with severe eosinophil infiltration —outbreak in a Japanese area other than Kyushu. Intern Med. 2002:41:574-9.

5. Izumikawa K, Kohno Y, Izumikawa K, Hara K, Hayashi H, Maruyama H, et al. Eosinophilic pneumonia due to visceral larva migrans possibly caused by Ascaris suum: a case report and review of recent literatures. Jpn J Infect Dis. 2011;64:428-32.
6. Miller LA, Colby K, Manning SE, Hoenig D, McEvoy E, Montgomery S, et al. Ascariasis in humans and pigs on small-scale farms, Maine, USA 2010-2013. Emerg Infect Dis. 2015;21:332-4.

7. Taylor HL, Spagnoli ST, Calcutt MJ, Kim DY. Aberrant Ascaris suum nematode infection in cattle, Missouri, USA. Emerg Infect Dis. 2016;22:339-40.

8. Nadler SA, Hudspeth DS. Ribosomal DNA and phylogeny of the Ascaridoidea (Nemata: Secernentea): implications for morphological evolution and classification. Mol Phylogenet Evol. 1998;10:221-36.

9. Wickramasinghe S, Yatawara L, Rajapakse R, Agatsuma T. Toxocara canis and Toxocara vitulorum: molecular characterization, discrimination, and phylogenetic analysis based on mitochondrial (ATP synthase subunit 6 and 12S) and nuclear ribosomal (ITS-2 and 28S) genes. Parasitol Res. 2009;104:1425-30.

10. Vlaminck J, Nejsum P, Vangroenweghe F, Thamsborg SM, Vercruysse J, Geldhof P. Evaluation of a serodiagnostic test using Ascaris suum haemoglobin for the detection of roundworm infections in pig populations. Vet Parasitol. 2012;189:267-73.

\section{Publisher's Note}

Springer Nature remains neutral with regard to jurisdictional claims in published maps and institutional affiliations.
Ready to submit your research? Choose BMC and benefit from:

- fast, convenient online submission

- thorough peer review by experienced researchers in your field

- rapid publication on acceptance

- support for research data, including large and complex data types

- gold Open Access which fosters wider collaboration and increased citations

- maximum visibility for your research: over $100 \mathrm{M}$ website views per year

At BMC, research is always in progress.

Learn more biomedcentral.com/submissions 